Pobrane z czasopisma Wschód Europy http://journals.umcs.pl/we Data: 26/04/2023 09:41:48

D0I:10.17951/we.2019.5.1.101-117 $\quad$ Wschód Europy • Восток Европы • East of Europe vol 5, $1 / 2019$

Дарья Щеглова

ORCID: https://orcid.org/0000-0002-5196-8607

Воронежский государственный университет, Россия

\title{
Демократия и факторы социально-экономического развития: применение качественного сравнительного анализа на примере российского кейса
}

Для стран постсоветского пространства и гибридных режимов различного толка важно понимать, какие причины могут привести к дисфункции демократических институтов, правового государства, что препятствует развитию самоорганизации и гражданского общества. Для стран, граничащих с Россией или находящихся в зоне ближайшего геополитического влияния это особенно актуально для понимания того, каков тренд развития и куда он может «свернуть».

Современные страны сталкиваются с универсальными вызовами публичной сферы: от эффектов постправды до «консервативной волны». Глобальные сравнительные исследования показывают неутешительные тренды сворачивания свободы прессы, кризиса институтов публичной власти и рост недоверия к политикам.

Социально-экономические показатели обычно рассматриваются как факторы, влияющие на эффективность, устойчивость демократии и снижающие протестный потенциал. Но и эти постулаты сегодня подвергаются эрозии и оказывается, что в разных группах стран классическая гипотеза Сеймура Липсета «чем выше социально-экономические показатели, тем устойчивее демократия» находит все меньше подтверждений. Более того, сама демократия обретает все больше и больше специфичных «форм» (гибридная, переходная, цифровая, старая/новая и т.п.). Можно ли в этой «мозаике» выявить какие-то общие тенденции?

В качестве гипотезы мы использовали тезис С. Липсета о зависимости уровня социально-экономического развития и потенциала «сохраняемости» демократических институтов. Главной проблемой в данном случае является то, с каким «мерилом» этих процессов можно подойти к различным группам стран, учитывая нарастающую неравномерность социально-экономической дифференциации. Релевантно ли сравнивать, например, англосаксонские стра- 
ны и Восточную Европу? Можно ли говорить о потенциале «сохраняемости» институтов демократии в странах, где она существует не более 30 лет, ставя их в один ряд с территориями, на которых демократические практики формировались столетиями?

С методологической точки зрения это решаемая проблема, и она заключается в поиске оснований для группировки стран по ряду признаков так, чтобы страны внутри этой группы можно было сравнивать и делать обоснованные выводы о «крепости» или «слабости» демократии там.

Качественный сравнительный анализ (КАС), основанный на комбинаторном методе (configurational methods) использует средства математической логики и предназначен для анализа взаимосвязи условий на уровне конкретного случая ${ }^{1}$. Качественный сравнительный анализ тем самым видится как дополнение к часто используемым методам корреляционного и регрессионного анализов. Более того, некоторые ученые, использующие КАС, отмечают, что он может стать альтернативой знакомых нам методологических единиц анализа - переменных, показателей, корреляций и т.п. Суть в том, что этот тип анализа имеет дело с комплексной каузальностью, при которой различные комбинации причинных факторов способны генерировать один и тот же результат. Метод КСА дает понимание того, какие аспекты необходимо рассмотреть в case study, применяемом к конкретной стране (в нашем случае, к Российской Федерации).

Задача данной статьи - посмотреть, какова специфика российских факторов демократизации, используя метод качественного сравнительного анализа. Метод качественного сравнительного анализа (КСА) применительно к кейсу России опирается на проведенные ранее исследования в рамках этой методологии, которые выявили пороговые значения социально-экономических показателей, оказывающиеся значимыми при сохранении или, наоборот, кризисе, демократических институтов ${ }^{2}$.

Общий обзор нескольких групп стран позволит нам понять, какие факторы оказываются значимыми для сохранения или упадка демократии, а какие второстепенными. Это необходимо для того, чтобы проанализировать их более развернуто в случае с Россией.

1 Ragin Charles C., What is Qualitative Comparative Analysis (QCA)? http://eprints.ncrm.ac.uk/250/1/ What_is_QCA.pdf, доступ 28 XII 2018.

2 Towards a Comparative Analysis of Democratic Innovations: Lessons from a pilot $f_{s-Q C A}$ of Participatory Budgeting. - ECPR General Conference Paper 2011 - https://pdfs.semanticscholar. org/d5f5/41df858a98833b4272b32e1a8fc6414338c5.pdf, доступ 28 XII 2018; Kołczyńska M., Democracy and Trust: A Quantitative and Qualitative Comparative Analysis of European Countries/ the 4th ECPR Graduate Conference, Bremen, July 4th-6th, 2012, https://ecpr.eu/Filestore/ PaperProposal/843992ca-f6aa-45ba-b355-f5ee1b2342ca.pdf, доступ 28 XII 2018; Schneider C. Q., Wagemann C., Reducing complexity in qualitative comparative analysis (QCA): remote and proximate factors and the consolidation of democracy, „European journal of political research” 2006, august, p. 751-786. 
Pobrane z czasopisma Wschód Europy http://journals.umcs.pl/we

Data: 26/04/2023 09:41:48

Демократия и факторы социально-экономического развития: применение качественного...

Группировка европейских стран по тому сохранилась (1) или нет (0) демократия (Survival) покажет, в каких группах стран социально-экономические факторы оказали влияние на сохранение демократии, а в каких реализовались другие модели.

Таблица 1. Группировка европейских стран по факторам, приводящим к сохранению или упадку демократии

\begin{tabular}{|l|l|l|l|l|l|l|}
\hline CASED & GNPCAP & URBANIZA & LITERACY & INDLAB & GOVSTAB & SURVIVAL \\
\hline AUS & 1 & 0 & 1 & 1 & 0 & 0 \\
\hline $\begin{array}{l}\text { BEL, CZE, } \\
\text { NET, UK }\end{array}$ & 1 & 1 & 1 & 1 & 1 & 1 \\
\hline EST & 0 & 0 & 1 & 0 & 1 & 0 \\
\hline FRA, SWE & 1 & 0 & 1 & 1 & 1 & 1 \\
\hline GER & 1 & 1 & 1 & 1 & 0 & 0 \\
\hline $\begin{array}{l}\text { GRE, POR, } \\
\text { SPA }\end{array}$ & 0 & 0 & 0 & 0 & 0 & 0 \\
\hline HUN, POL & 0 & 0 & 1 & 0 & 0 & 0 \\
\hline FIN, RE & 1 & 0 & 1 & 0 & 1 & 1 \\
\hline ITA, ROM & 0 & 0 & 0 & 0 & 1 & 0 \\
\hline
\end{tabular}

Источник: Расчеты автора.

Данные позволяют нам сделать вывод о том, что в тех странах, где был высокий уровень ВВП и зафиксирована значительная стабильность правительства, это привело к сохранению демократических институтов. Этому тезису соответствуют кейсы Бельгии, Чехии, Нидерландов, Великобритании, Финляндии, Ирландии, Франции, Швеции.

Что касается групп стран, где наблюдался упадок демократии, то в них есть подгруппы тех, где главным фактором оказался уровень государственного управления (стабильность правительства). Так, высокий ВВП в сочетании со стабильностью правительства привел к сохранению демократии в Бельгии, Чехии, Нидерландах, Великобритании. Что отличает эти страны от других, покрываемых минимальным решением (Франция, Швеция)? В каких группах стран важно учитывать объем ВВП, а в каких - политический фактор?

Для проверки этих зависимостей мы проанализировали аналогичным методом другой набор стран. Группировка следующих 11 стран: Армения, Азербайджан, Бахрейн, Грузия, Израиль, Иордания, Ирак, Сирия, Турция, Йемен, Саудовская Аравия) показала иные результаты. Указанные страны были взяты с целью продемонстрировать степень того, как это предположение может быть рабочей в «незападных» странах. Под «незападными» мы понимаем те, которые можно охарактеризовать по типологии Люсьена Пая «незападным политическим процессом»³.

3 Пай Л., Незападный политический процесс, „Политическая наука” 2003, №2, с. 66-85. 
Pobrane z czasopisma Wschód Europy http://journals.umcs.pl/we

Data: 26/04/2023 09:41:48

104

Дарья Щеглова

Пороговые значения для нашей гипотезы для этой группы стран были изменены в сторону уменьшения размера ВВП (как основного экономического показателя). Это было сделано целенаправленно, учитывая специфику их экономического развития.

Таблица 2. Группировка стран с «незападным» типом политического процесса по социально-экономическим показателям и качеству демократии

\section{Truth-Table:}

\begin{tabular}{|c|c|c|c|c|c|}
\hline CASE ID & GNPCAP & URBANIZA & HIGHER EDUCATION & POPULATION & SURVIVAL \\
\hline YEM & 0 & 0 & 0 & 1 & 0 \\
\hline IRA, SAR & 0 & 1 & 0 & 0 & 0 \\
\hline $\operatorname{ARM}(0), \operatorname{AZER}(0), \operatorname{GEO}(1), \operatorname{JOR}(0)$ & 0 & 1 & 1 & 0 & $\mathrm{C}$ \\
\hline $\mathrm{BAH}$ & 0 & 1 & 1 & 1 & 0 \\
\hline $\operatorname{ISR}(1), \operatorname{TUR}(1), \mathrm{SA}(0)$ & 1 & 1 & 1 & 0 & $\mathrm{C}$ \\
\hline
\end{tabular}

Created with Tosmana Version 1.6

Источник: Расчеты автора.

Мы видим одну отчетливую положительную конфигурацию (Бахрейн), две отрицательных (Йемен, Ирак, Сирия) и две противоречивых конфигурации (Армения, Азербайджан, Грузия, Иордания, Израиль, Турция, Саудовская Аравия). Значит, гипотеза Липсета (в представленной здесь интерпретации) не работает для 7 из 11 случаев. Особенно показательна вторая конфигурация, в которой имеются все положительные условия, но результат Саудовской Аравии противоречит. Это и есть пример противоречивой конфигурации, которую необходимо разрешить. Было решено добавить еще одно условие - стабильность правительства (governmental stability). Пороговое значение для нее выбрано следующее: [0] если за выбранный срок сменилось 10 или более кабинетов правительства, [1] если меньше. Пересматриваем исходную таблицу.

Таблица 3. Группировка стран с «незападным» типом политического процесса по социально-экономическим показателям и качеству демократии с включением показателя эффективности госуправления

Truth-Table:

$\begin{array}{lccccc} & \text { CASE ID } & \text { GNPCAP URBANIZA } & \text { HIGHER EDUCATION } & \text { POPULATION SURVIVAL GOVST } \\ \text { YEM } & 0 & 0 & 0 & 0 & 0 \\ \text { SYR } & 0 & 1 & 0 & 0 & 0 \\ \text { IRA } & 0 & 1 & 0 & 1 & 0 \\ \text { ARM } & 0 & 1 & 1 & 0 & 0 \\ \text { AZER(0), BAH(0), JOR(1) } & 0 & 1 & 1 & 1 & 0 \\ \text { GEO } & 0 & 1 & 1 & 1 & 0 \\ \text { SA } & 1 & 1 & 1 & 1 & 1 \\ \text { ISR(1), TUR(0) } & 1 & 1 & 1 & 1 & 0 \\ \end{array}$

Created with Tosmana Version 1.6

Источник: Расчеты автора. 
Мы видим 4 отрицательных конфигурации (Йемен, Сирия, Ирак, Саудовская Аравия), две положительные конфигурации (Армения, Грузия) и две противоречивые конфигурации (Азербайджан, Бахрейн, Иордания, Израиль, Турция). Турция содержит противоречивые данные и в первой, и во второй группировках и отличается по всем факторам от остальных стран. В частности, уровень стабильности правительства играет для нее большую роль в сохранении ВВП, чем экономическое развитие.

Обратимся к российскому кейсу. Мы попробовали поочерёдно включить Россию в обе группы рассмотренных выше стран с различным типом политического процесса и посмотреть на результаты группировки. В случае с европейскими странами Россия переходит пороговое значение по показателям образованности, урбанизации, прироста населения, и стабильности правительства (governmental stability). При этом институты демократии сохраняются. Вопрос «качества» пока оставим за скобками. Таким образом, факторами, которые не «дотягивают» до полного соответствия гипотезе Липсета для России остается ВВП на душу населения. Но является ли он ключевым?

Стабильность правительства и демократия - еще одна «пара», которую необходимо посмотреть внимательнее. Этот фактор оказался решающим во влиянии на демократию в Турции, Саудовской Аравии, Греции, Испании, Португалии, Польше, Венгрии и Румынии. Рассмотрим фактор работы правительства (который выступил в нашем исследовании, как индикатор качества государственного управления), как отдельный кейс.

Показателями качества государственного управления мы рассматривали шесть индексов государственного управления, разработанных по методологии Мирового Банка (World Bank Policy Research: Governance Matters 1996-2013).

Таблица ниже содержит совокупные рейтинги России по шести индексам:

1. Учёт мнения населения и подотчётность государственных органов.

2. Политическая стабильность и отсутствие насилия.

3. Эффективность работы правительства.

4. Качество законодательства.

5. Верховенство закона.

6. Сдерживание коррупции.

Таблица 4. Средние показатели России по шести индексам работы Правительства.

\begin{tabular}{|c|c|c|c|c|c|c|}
\hline $\begin{array}{c}\text { Страна/Номер } \\
\text { индекса }\end{array}$ & 1 & 2 & 3 & 4 & 5 & 6 \\
\hline Россия & 18.96 & 22.27 & 43.06 & 37.32 & 24.6 & 16.75 \\
\hline
\end{tabular}

Источник: World Bank Policy Research: Governance Matters 1996-2013 - URL: http://info. worldbank.org/governance/wgi/pdf/wgi.pdf 
Pobrane z czasopisma Wschód Europy http://journals.umcs.pl/we

Data: 26/04/2023 09:41:48

Содержательно важным для нас в этих индексах являются два: эффективность правительства (3) и включенность населения (1). Мы предполагаем, что именно роль участия граждан в управлении, учет их мнения, способность Правительства видеть, понимать и учитывать запросы граждан здесь ключевой аспект. Этот фактор оказывает значительное влияние на потенциал сохранения демократии.

\begin{tabular}{|c|c|c|c|c|c|c|c|c|c|}
\hline Indicator & Country & Year & \multicolumn{4}{|c|}{$\begin{array}{l}\text { Percentile Rank } \\
(0 \text { to } 100)\end{array}$} & ? & & \\
\hline \multirow[t]{3}{*}{ Voice and Accountability } & \multirow[t]{3}{*}{ Russian Federation } & 2007 & - & & & & & & \\
\hline & & 2012 & $\longrightarrow$ & & & & & & \\
\hline & & 2017 & $\longrightarrow$ & & & & & & \\
\hline \multirow{3}{*}{$\begin{array}{l}\text { Political Stability and } \\
\text { Absence of } \\
\text { Violence/Terrorism }\end{array}$} & \multirow[t]{3}{*}{ Russian Federation } & 2007 & 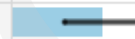 & & & & & & \\
\hline & & 2012 & - & & & & & & \\
\hline & & 2017 & $\longrightarrow$ & & & & & & \\
\hline \multirow[t]{3}{*}{ Government Effectiveness } & \multirow[t]{3}{*}{ Russian Federation } & 2007 & & & 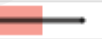 & & & & \\
\hline & & 2012 & & - & - & & & & \\
\hline & & 2017 & & & $\longrightarrow$ & & & & \\
\hline \multirow[t]{3}{*}{ Regulatory Quality } & \multirow[t]{3}{*}{ Russian Federation } & 2007 & & & 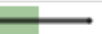 & & & & \\
\hline & & 2012 & & - & 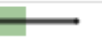 & & & & \\
\hline & & 2017 & & - & & & & & \\
\hline \multirow[t]{3}{*}{ Rule of Law } & \multirow[t]{3}{*}{ Russian Federation } & 2007 & - & & & & & & \\
\hline & & 2012 & $\longrightarrow$ & & & & & & \\
\hline & & 2017 & $\longrightarrow$ & & & & & & \\
\hline \multirow[t]{4}{*}{ Control of Corruption } & \multirow[t]{3}{*}{ Russian Federation } & 2007 & $\longrightarrow$ & & & & & & \\
\hline & & 2012 & $\longrightarrow$ & & & & & & \\
\hline & & 2017 & 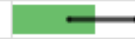 & & & & & & \\
\hline & & & $\begin{array}{lll}0 & 10 & 20\end{array}$ & 30 & $40 \quad 50$ & 60 & 70 & 80 & 90100 \\
\hline
\end{tabular}

Рис. 1 Индикаторы качества государственного управления в России Источник: URL: http://info.worldbank.org/governance/WGI/\#reports

В Российской Федерации показатели вовлеченности населения в контроль за деятельностью Правительства и управление оказывается крайне низким, притом, что эффективность правительства высокая. Если сравнить по этим показателям Россию с Турцией и Саудовской Аравией (в которых, как было указано выше, наблюдается схожая зависимость фактора государственного управления и сохранения демократии), то мы видим, что эффективность Правительства РФ увеличивается и достигает показателей этих стран, но при этом, уровень контроля коррупции остается стабильно низким (Рис. 1).

Российский кейс отличается еще одним показателем - степенью вовлеченности населения в управление. Здесь Россия значительно отстает как от группы стран с «незападным» политическим процессом, так и от сгруппированных по схожим факторам влияния на демократию европейских стран (Рис. 2). 
Pobrane z czasopisma Wschód Europy http://journals.umcs.pl/we

Data: 26/04/2023 09:41:48

Демократия и факторы социально-экономического развития: применение качественного... 107

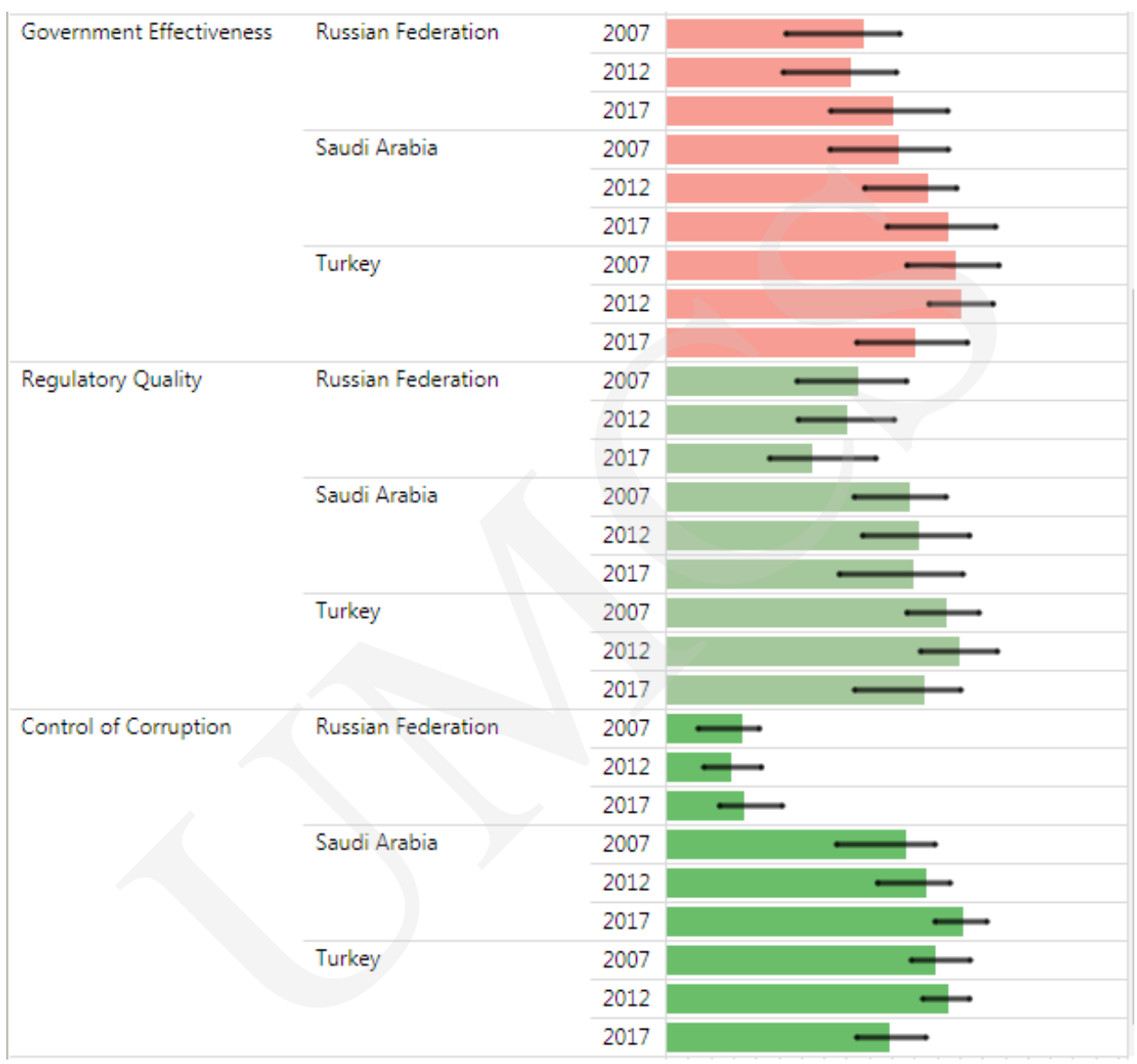

Рис. 2 Сравнение показателей качества государственного управления России, Саудовской Аравии и Турции.

Источник: URL: http://info.worldbank.org/governance/WGI/\#reports

Таким образом, для групп стран с «незападным» политическим процессом - качество госуправления (в лице работы правительства), как фактор функционирования демократии - лучше всего описывают ситуацию такие его составляющие, как: учёт мнения населения, подотчётность государственных органов и сдерживание коррупции. На этих темах в 2008 году строил свою политическую программу тогдашний Президент России Д.А. Медведев, на которого возлагались большие надежды на политическую модернизацию, но которые так и не оправдались ${ }^{4}$.

4 R. Sakwa, The crisis of Russian democracy: The dual state, factionalism and the Medvedev succession, Cambridge University Press 2010, pp. 1-398. 
Pobrane z czasopisma Wschód Europy http://journals.umcs.pl/we

Data: 26/04/2023 09:41:48

В странах с «западным» типом политического процесса эти показатели максимально отличались от остальных у тех стран, у которых, согласно группировки по методу качественного анализа были наибольшие проблемы с функционированием института демократии.

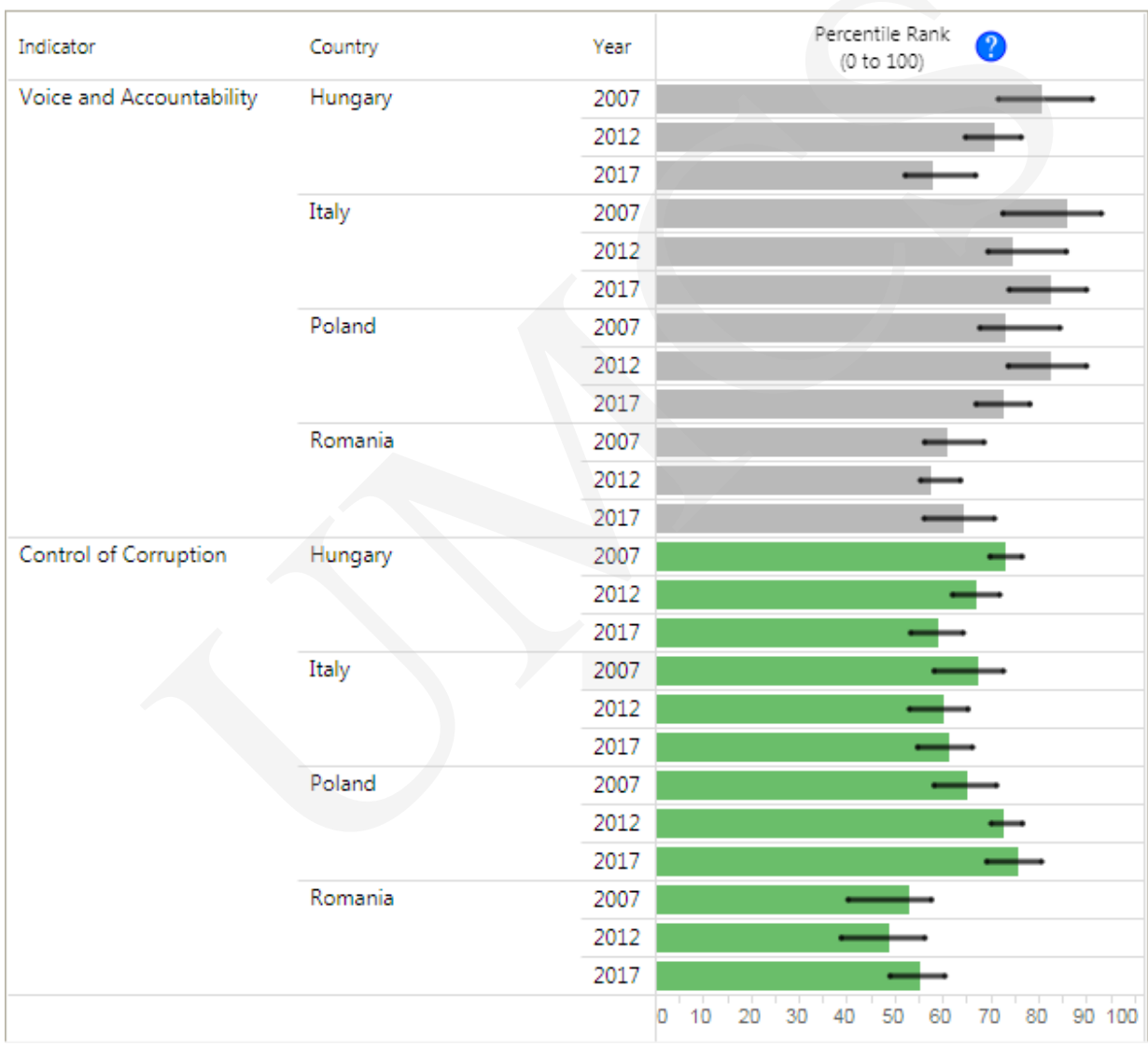

Рис. 3 Сравнение показателей качества государственного управления в странах, где этот фактор оказал наибольшее влияние на «качество» демократии.

Источник: URL: http://info.worldbank.org/governance/WGI/\#reports

Еще одним методом описания ситуации с уровнем демократизации и его зависимостью от социально-экономических факторов является поиск зависимости уровня демократии (измерялся уровнем демократизации по методике «Дома Свободы») и экономическими показателями. В качестве индикаторов уровня демократии в данном случае брались данные по демократизации 5 .

5 База Данных Freedom House - отчет по России - https://freedomhouse.org/report/nationstransit/2018/russia, доступ 28 XII 2018. 
Pobrane z czasopisma Wschód Europy http://journals.umcs.pl/we

Data: 26/04/2023 09:41:48

Демократия и факторы социально-экономического развития: применение качественного...

Таблица 5. Уровень демократизации России (по данным исследования) - усредненные показатели

\begin{tabular}{|l|c|c|c|c|c|c|c|c|c|c|}
\hline Страна/год & 2006 & 2007 & 2008 & 2009 & 2010 & 2011 & 2012 & 2013 & 2014 & 2015 \\
\hline Россия & 5,02 & 4,48 & 4,26 & 3,92 & 3,74 & 3,59 & 3,39 & 3,32 & 3,24 & 3,17 \\
\hline
\end{tabular}

Источник: Freedomhouse databse URL: https://freedomhouse.org/report/freedom-world/free dom-world-2018

Таблица 6. Уровень авторитаризма России (по данным исследования Nations in Transit) - усредненные показатели (диапазон шкалы от 1 до 7)

\begin{tabular}{|c|c|c|c|c|c|c|c|c|c|}
\hline Год & 2009 & 2010 & 2011 & 2012 & 2013 & 2014 & 2015 & 2016 & 2017 \\
\hline Показатель & 6,11 & 6,14 & 6,18 & 6,18 & 6,21 & 6,29 & 6,46 & 6,5 & 6,57 \\
\hline
\end{tabular}

Источник: Freedomhouse databse - URL: https://freedomhouse.org/report/nations-transit/2018/ russia

Очевидна тенденция снижения уровня демократизации в России и это достаточно очевидный факт, о котором написано уже немало. Наша задача - сфокусироваться на тех факторах, которые оказывают на это сильное влияние. Обратим внимание на несколько основных экономических показателей (безработица и ВВП) и фактор, выделенный нами, как основной для сохранения демократии (уровень вовлеченности населения в управление).

Таблица 7. Корреляция уровня демократии и основных социально-экономических показателей за последние 20 лет (Россия)

\begin{tabular}{|l|c|}
\hline \multicolumn{1}{|c|}{ Статистические показатели } & Значение коэффициента корреляции \\
\hline Уровень демократии и безработица & $-0,42$ \\
\hline Уровень демократии и размер ВВП & $-0,4$ \\
\hline $\begin{array}{l}\text { Уровень демократии и качество контроля за } \\
\text { правительством }\end{array}$ & 0,89 \\
\hline
\end{tabular}

Источник: расчеты автора

Данные показывают нам, что качество контроля за Правительством со стороны населения сильно коррелирует с качеством демократии. Однако в России мы наблюдаем, казалось бы, парадоксальную ситуацию, когда подконтрольность правительства населению сокращается (Рис. 4), а экономическая эффективность (измеряемая нами уровнем ВВП, безработицы и рядом других основных макроэкономических показателей) и эффективность Правительства возрастает. 
Pobrane z czasopisma Wschód Europy http://journals.umcs.pl/we

Data: 26/04/2023 09:41:48

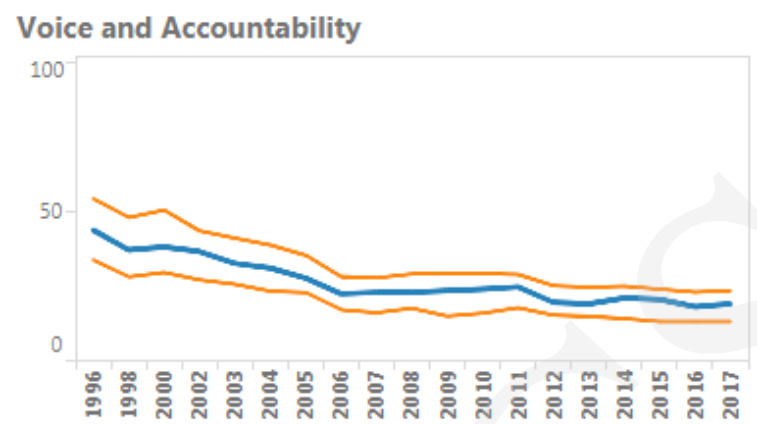

Government Effectiveness

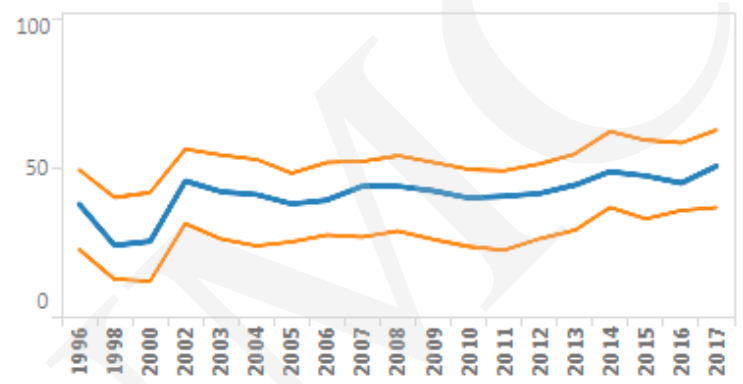

Рис. 4 Показатели качества государственного управления для России: вовлеченность населения (voice and accountability) и эффективность Правительства (Government effectiveness)

Источник: - URL: http://info.worldbank.org/governance/WGI/\#reports

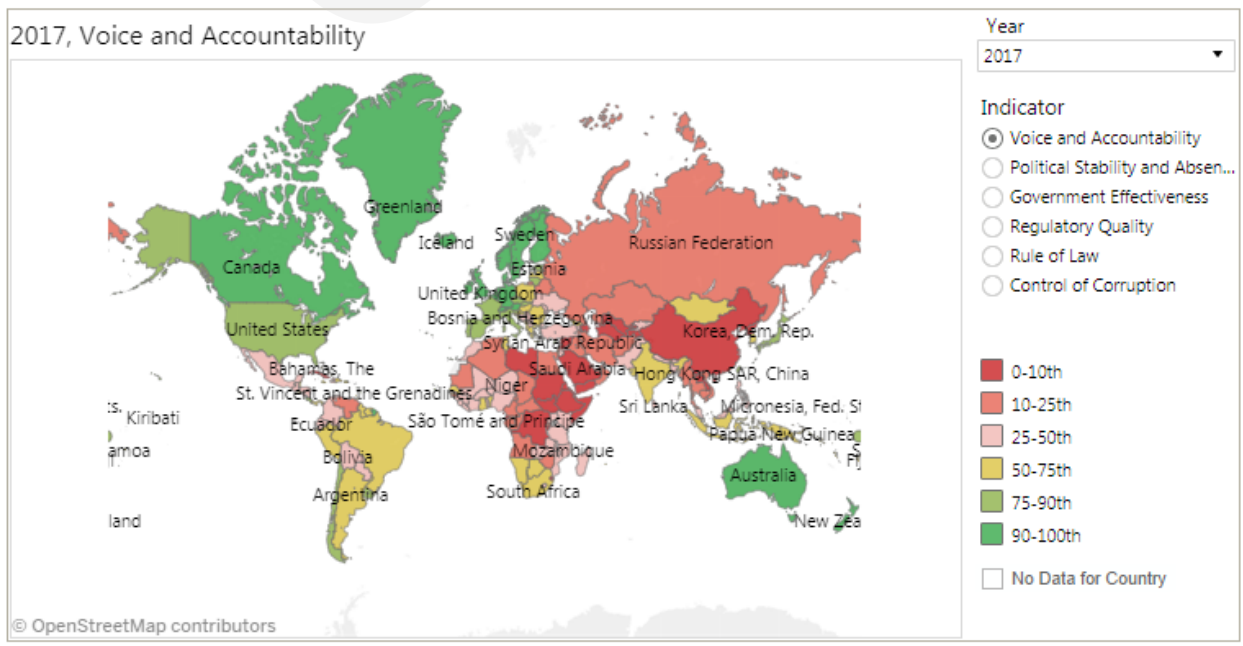

Рис. 5 Показатели качества государственного управления в 2017 г. (вовлеченность населения): мировые тенденции.

Источник: - URL: http://info.worldbank.org/governance/WGI/\#reports 
Pobrane z czasopisma Wschód Europy http://journals.umcs.pl/we

Data: 26/04/2023 09:41:48

Демократия и факторы социально-экономического развития: применение качественного...

111

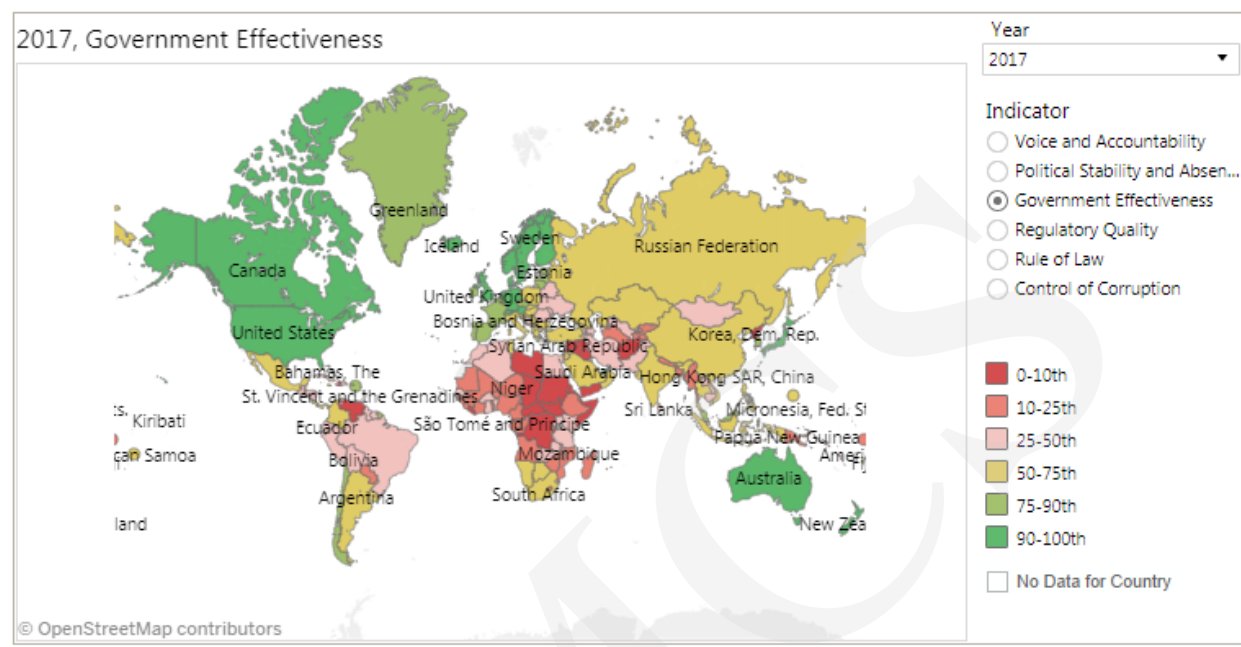

Рис. 6 Показатели качества государственного управления в 2017 г. (Эффективность правительства): мировые тенденции

Источник: - URL: http://info.worldbank.org/governance/WGI/\#reports

Если обратить внимание на общемировой тренд, то уровень вовлеченности населения в государственное управление падает. Россия по этим показателям оказывается в группе стран с «гибридными» режимами, но при этом с достаточно высоким уровнем экономического развития. Важно отметить, что практически во всех странах этой группы (50-75 в рейтинге на карте Рис. 6) показатель эффективности Правительства очень высок.

Какие риски для сохранения демократии несет такая ситуация? Чем может обернуться дальнейшее сокращение контроля населения за Правительством? Отвечая на этот вопрос, мы обратились к такому показателю, как протестная активность (протестный потенциал). Логично предположить, что чем меньше возможность населения контролировать деятельность Правительства и участвовать в госуправлении, тем сильнее будет протестная активность, а протестный потенциал будет увеличиваться.

Посмотрим общемировые тенденции и постараемся понять, насколько Россия «вписывается» в глобальные тренды, связанные с протестным поведением и «качеством» демократии. Зависимость уровня и характера протестных настроений от типа демократии (старая, новая, «третьей волны», гибридная и т.п.) была одной из главных исследовательских тем в период 2005-2012 гг. В основном, авторы сосредотачивали свое внимание на том, как современные демократические выборы, соревновательная система приводит к возрастанию политического протеста в демократиях различного типа. Предполагалось, что в старых демократиях уровень политического протеста ниже, чем в новых, но последние исследования показали, что это не совсем так. 
Крайне интересные данные были получены по протестному потенциалу граждан после исследования ряда старых и новых демократий. Так, в весьма разных странах, таких как Венгрия, Ирландия, Россия и Великобритания показатель агрегации протестного потенциала индивидов находится на одинаковом уровне (показатель между 1,5 и 2), а наиболее высокий и низкий результаты показали как раз страны «старых» демократий (established democracies) - Италия - 3,81, Япония - 0, 68).

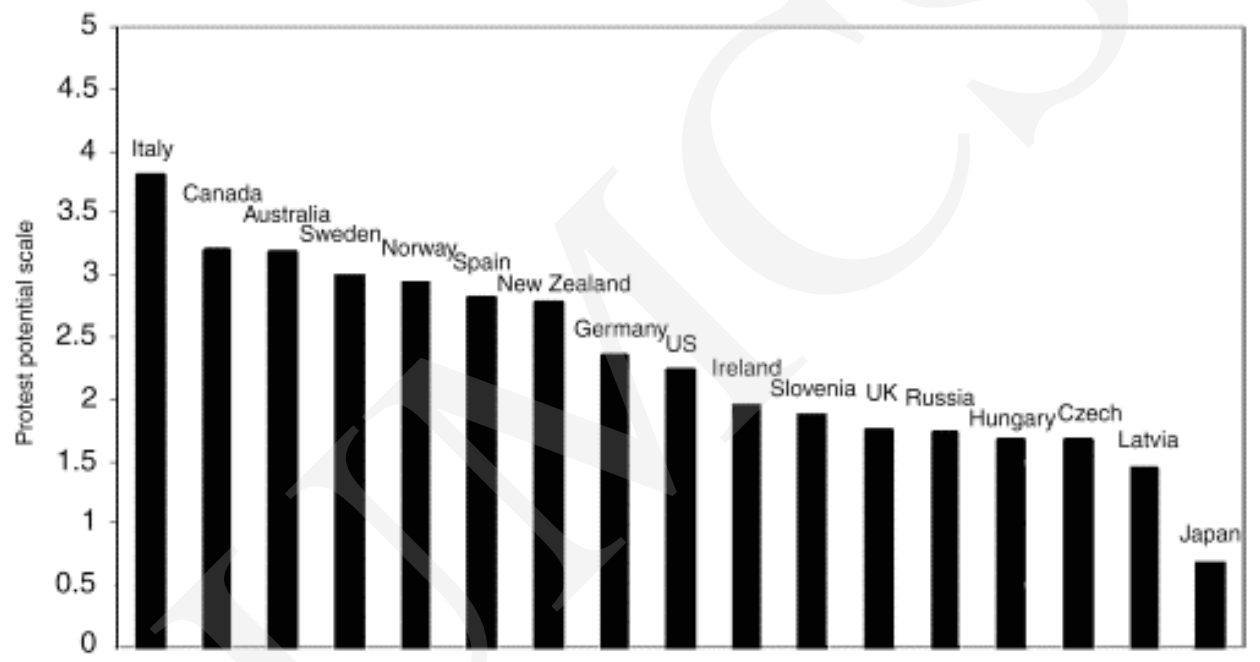

Рис. 7 Протестный потенциал в семнадцати демократиях

Источник: Anderson Ch. J., Mendes S. M. Learning to Lose: Election Outcomes, Democratic Experience and Political Protest Potential // Britain Journal of Political science. - URL: https://core. ac.uk/download/pdf/55604172.pdf

Если посмотреть на группировку этих стран по другим показателям становится понятным, что протестный потенциал не выступает ключевым фактором сохранения или коллапса демократии. Другими словами - возрастание протестного потенциала не является важным фактором, влияющим на функционирование демократических институтов.

Интересен тот факт, что принадлежность к большинству или меньшинству оказывает сильное воздействие на протестный потенциал в странах с недолгим демократическим «стажем» правления. Причины этого видятся в слабых «корнях» гражданского общества. Граждане в старых демократиях оказываются заинтересованными в том, чтобы все группы населения (а не только большинство-победители) были вовлечены в публичную сферу. Большинство начинает понимать важность включения в принятие публичных решений того специфичного сегмента избирателей, которые могут породить почву для политического протеста. Таким образом, в старых демократиях протест формируется не 
столько в группах «проигравших» и «потенциально проигравших», но и среди победителей-большинства. В новых демократиях большинство-победители не обладают демократическими ценностями, практикой длительного конвенционального участия. В этом случае крайне необходимо их «гражданское научение», так как именно они остаются потенциальной почвой для протеста'.

Было доказано, что на протест, равно как и на стабильность демократии оказывают влияние экономические факторы. Так, в начале 2000-х гг. объемное коллективное исследование политического протеста на основе данных the World Values Survey, показало, что факторы макроуровня (экономическое и политическое развитие) значительно влияют на уровень протеста. Многоуровневая модель, разработанная Р. Далтоном, А. ван Сиклом и С. Велдоном показала эффективность в прогнозе локальных протестов, эта же модель показала, что основные претензии протестующих обращены не к правительству или властям, а в результате такого экономического развития, которое редуцирует ресурсы тех, у кого есть сформировавшиеся требования, требующие артикуляции ${ }^{7}$.

Что касается российского кейса, то в нем мы видим тенденцию роста протестной активности и потенциальной готовности к ней.

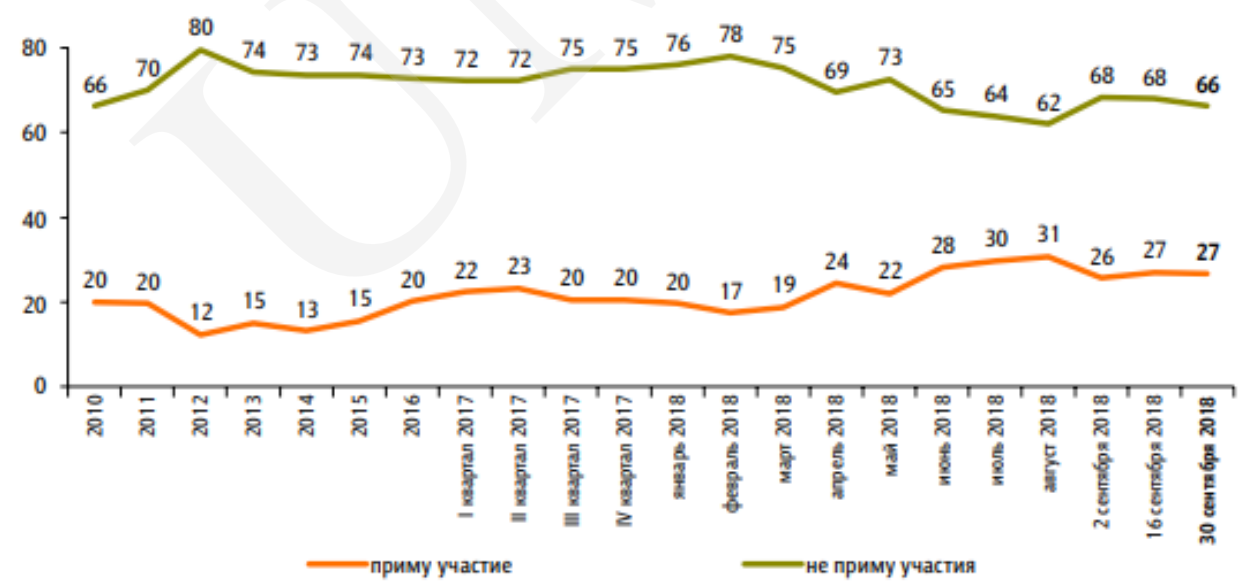

Рис. 8 Возможность принятия участия в акциях протеста россиян (на основе данных Фонда «Общественное мнение» (в\% к общему числу респондентов)

Источник: База данных Фонда «общественное мнение» - URL: http://bd.fom.ru/report/ map/dominant/dom_3918/d391804

6 Anderson Ch. J., Mendes S. M., Learning to Lose: Election Outcomes, Democratic Experience and Political Protest Potential, „Britain Journal of Political Science” 2005, No 36, pp. 91-111.

7 Dalton U., Sickle A., Weldon S., The Individual-Institutional Nexus of Protest Behaviour, "British Journal of Political Science" 2010, Vol. 40, Issue 1, pp. 51-73. 
Одновременно с этим падает уровень доверия к правительству при сохранении высокого уровня доверия к армии, церкви и силовым структурам ${ }^{8}$.

Таким образом, качественный сравнительный анализ, позволивший сосредоточиться на методе кейс-стади, и индексный анализ показывают схожие тенденции во взаимосвязи социально-экономических факторов и функционирования демократии.

1. Группировать страны для качественного сравнительного анализа при изучении потенциала «живучести» демократии лучше всего по принципам типологии Л. Пая - с выраженным «западным» или «незападным» политическим процессом.

2. Социально-экономические факторы в классической гипотезе С. Липсета необходимо дополнить показателями эффективности государственного управления в вопросах контроля коррупции, вовлеченности населения в государственное управление и степень учета общественного мнения правительственными структурами, контроль за коррупцией.

3. Экономический фактор «обнаруживает себя», как фактор демократизации достаточно редко. Эта тенденция обозначила себя сравнительно недавно - в конце 90-х начале 2000-х гг.

4. Экономический фактор оказывается решающим только в отдельных группах стран. Достигая определенного «порогового значения» (различный для разных групп стран), его влияние на сохранение демократии снижается.

5. Уровень урбанизации также не оказывает значительного влияния на демократизацию. Однако, тут можно предположить, что стоит качественно пересмотреть понятие урбанизации сквозь призму признаков городской культуры (как это делают сейчас исследователи в World Values Survey (WVS)) и степени требовательности граждан к среде обитания без привязки к размерам территории.

6. Уровень образованности (измеряемый нами в долях людей с высшим образованием) не оказывает влияния на развитие демократизации и становится все более формальным в эпоху самообразования и онлайн-ресурсов.

7. Россия, с точки зрения примененного подхода, оказывается очень схожа в вопросах факторов, влияющих на сохранение или сворачивание демократии с Турцией, Саудовской Аравией (из группы стран с «незападным» политическим процессом»), а также с Венгрией, Италией, Польшей и Румынией. Эта схожесть заключается в том, какие факторы оказываются

8 Институциональное доверие, Левада-Центра: https://www.levada.ru/2018/10/04/ institutsionalnoe-doverie-4/, доступ 28 XII 2018; Деятельность общественных институтов, база данных ВЦИОМ, - URL: https://wciom.ru/news/ratings/odobrenie_deyatelnosti_ obshhestvennyx_institutov/, доступ 28 XII 2018. 
Pobrane z czasopisma Wschód Europy http://journals.umcs.pl/we

Data: 26/04/2023 09:41:48

Демократия и факторы социально-экономического развития: применение качественного...

«решающими» в сохранении и поддержании качества демократии. При этом, уровень демократизации России и перечисленных стран разнится (и часто очень значительно).

Аннотация: В статье обращается внимание на то, что классический постулат о том, что социально-экономические показатели являются ключевыми факторами, влияющими на эффективность, устойчивость демократии и снижающие протестный потенциал сегодня подвергается эрозии. Рассматривается новое прочтение классической гипотезы С. Липсета о зависимости социально-экономического развития и демократии. Применен метод качественного сравнительного исследования, индексный анализ; отмечается то, какие составляющие качества государственного управления оказываются решающими в случае с Россией и рядом других стран. Сделан вывод о том, что темпы экономического развития не оказывают значительного влияния на развитие демократии, решающим для сохранения демократии и снижения протестного потенциала оказывается фактор вовлечения населения в управление государством.

Ключевые слова: Качественный сравнительный анализ, демократия, Россия, социально-экономическое развитие, государственное управление.

\section{Demokracja i czynniki rozwoju społeczno-gospodarczego: zastosowanie jakościowej analizy porównawczej na przykładzie przypadku rosyjskiego}

Streszczenie: Artykuł zwraca uwagę na fakt, że klasyczny postulat o tym, iż wskaźniki społeczno-gospodarcze są kluczowymi czynnikami wpływającymi na skuteczność, trwałość demokracji i ograniczają społeczny potencjał protestacyjny, nie są już dziś aktualne. Rozważana jest nowa interpretacja klasycznej hipotezy S. Lipset na temat zależności rozwoju społeczno-gospodarczego i demokracji. W artykule zastosowano metodę jakościowych badań porównawczych, analizę indeksów, które wskazują, jakie elementy jakości administracji publicznej są decydujące w przypadku Rosji i wielu innych krajów. Stwierdza się, że tempo rozwoju gospodarczego nie ma znaczącego wpływu na rozwój demokracji; czynnik zaangażowania społeczeństwa w proces rządzenia ma kluczowe znaczenie dla utrzymania demokracji i zmniejszenia potencjału protestacyjnego.

Słowa kluczowe: jakościowa analiza porównawcza, demokracja, Rosja, rozwój społeczno-gospodarczy, administracja publiczna.

\section{Democracy and socio-economic scores of development: qualitative comparative analysis and Russian case}

Abstract: The author deals with the question of the interrelation between democracy and socioeconomic indicators. Author gives a new look at the classical hypothesis of S. Lipset about the dependence of socio-economic development and democracy. Using the method of qualitative comparative research and index analysis; it was noted that the components of the quality of public administration 
are crucial in the case of Russia and a number of other countries. It is concluded that the pace of economic development does not have a significant impact on the development of democracy; the factor of involving the population in government is crucial for maintaining democracy and reducing the protest potential.

Key words: Qualitative comparative analysis, democracy, Russia, socio-economic development, public administration.

\section{Источники и литература}

\section{Источники}

Deyatel'nost' obshchestvennykh institutov, VTSIOM: https://wciom.ru/news/ratings/odobrenie_deyatelnosti_obshhestvennyx_institutov/.

Institutsional'noye doveriye, Levada-Tsentr: https://www.levada.ru/2018/10/04/institutsionalnoe-doverie-4/.

Perekhodnyye obshchestva, Freedom House - otchet po Rossii -https://freedomhouse.org/report/nations-transit/2018/russia.

Pokazateli kachestva gosudarstvennogo upravleniya, Baza dannykh Mirovogo Banka, http://info.worldbank.org/governance/WGI/\#reports.

\section{Литература}

Alfred Jr., The failure of democratization in Russia: A comparative perspective, "Journal of Eurasian Studies" 2011/2.

Amy A., Inglehart R., Measuring Effective Democracy, "International Political Science Review" 2012.

Amy C. A., Welzel C., Measuring Effective Democracy. The Human Empowerment Approach, "Comparative Politics", April 2011.

Anderson Ch. J., Mendes S. M., Learning to Lose: Election Outcomes, Democratic Experience and Political Protest Potential, "Britain Journal of Political Science” 2005, No36.

DOl: https://doi.org/10.1017/S0007123406000056.

Dalton U., Sickle A., Weldon S., The Individual-Institutional Nexus of Protest Behaviour, "British Journal of Political Science" 2010, Vol. 40, Issue 1.

Hill D.W., Democracy and the Concept of Personal Integrity Rights, "Journal of Politics" 2016, 78 (3).

Joshi D., Maloy J., Peterson T., Popular vs. Elite Democratic Structures and International Peace, "Journal of Peace Research" 2016, 63(1).

Kołczyńska Marta, Democracy and Trust: A Quantitative and Qualitative Comparative Analysis of European Countries/ the 4th ECPR Graduate Conference, Bremen, July 4th-6th, 2012, https://ecpr.eu/ Filestore/PaperProposal/843992ca-f6aa-45ba-b355-f5ee1b2342ca.pdf/

Marcus A., The Internet and Democratization: The Development of Russian Internet Policy, "Demokratizatsiya: The Journal of Post-soviet Democratization" 2004/12.

Pay L., Nezapadnyy politicheskiy protsess, „Politicheskaya nauka” 2003, №2.

Ragin Charles C., What is Qualitative Comparative Analysis (QCA)? http://eprints.ncrm.ac.uk/250/1/ What_is_QCA.pdf/ 
Pobrane z czasopisma Wschód Europy http://journals.umcs.pl/we

Data: 26/04/2023 09:41:48

Демократия и факторы социально-экономического развития: применение качественного...

Sakwa R., The crisis of Russian democracy: The dual state, factionalism and the Medvedev succession, Cambridge University Press 2010.

Schneider C. Q., Wagemann C., Reducing complexity in qualitative comparative analysis (QCA): remote and proximate factors and the consolidation of democracy, "European journal of political research", august 2006, 45.

Towards a Comparative Analysis of Democratic Innovations: Lessons from a pilot fs-QCA of Participatory Budgeting. - ECPR General Conference Paper 2011 - https://pdfs.semanticscholar.org/d5f5/41df858a98833b4272b32e1a8fc6414338c5.pdf/ 